\title{
Supporting Mobile Professionals in Global Banking: The Role of Global ICT-Support Call-Centres
}

\author{
Adel Al-Taitoon and Carsten Sørensen \\ Department of Information Systems, London School of Economics and Political Science, London, UK
}

\begin{abstract}
The aim of this paper is to address the role of ICT-support call-centres in supporting mobile professionals in global organizations requiring constant and continuous access to information services. We in particular consider modern global banking firms where ICTs are intensively utilised for electronic transactional processing and in supporting banking professionals in accomplishing their global tasks across geographical locations and time zones. The use of ICTs by global mobile bankers is crucial to access real-time information. Mobile banking professionals experiencing technology failure or difficulties in accessing information services may lead to serious financial or operational consequences for the organization. ICT-support call-centres therefore play an important role in supporting the mobile bank professionals. This paper discusses how a global help desk unit accomplishes this role in a global banking organization. This is achieved through analysis of the call tickets from the global helpdesk tracking system. We conclude from the analysis of the empirical data that it is important to understand the support for mobile professionals in terms of the three phases of pre-mobility, in-mobility, and post-mobility. Each phase offers distinct challenges for the ICT support team.
\end{abstract}

Keywords: mobility, globalisation, banking, support, call centres, information and communication technology.

\section{Introduction}

Information and Communication Technology (ICT) departments in modern organizations are struggling to keep up with the demand for computing, rapid technology changes and the fundamental transformation of work [28]. Moreover, ICT support specialists and experts have been further challenged with the shift from the traditional functional hierarchy of the Industrialised Society with highly functionally divided labour supported by centralised mainframes towards the flat, networked, organization of the
Knowledge, Information or Service Economy, applying highly flexible, and possibly wireless, information infrastructures supporting knowledge work [11]. In their book The Support Economy, Zuboff and Maxmin [42] address the challenges for efficient production of goods and services. These challenges should be definitely addressed in this age of mobile ICTs. For instance, over the last decade, we have witnessed a large diffusion of mobile ICTs such as laptops, mobile phones, personal digital assistants, and tablet-PCs, together with a rapidly emerging mobile information and interaction services (e.g. emails, instant messaging, wireless applications, and location-based services), which have further transformed the work of mobile professionals [38]. This widespread diffusion of mobile computing devices and services creates added complexities for the computer services support staff in their day-to-day work in supporting mobile professionals.

In global organizations, where professionals require constant and timely access to global information for making decisions [27], the effectiveness of ICT support process becomes significantly important to ensure availability of global information services for mobile professionals. In modern global banking, for instance, the ongoing improvements of information processing, telecommunication, and financial technologies have enabled global banking professionals to access digitally represented products, process electronic transactions, administer larger information flows from different locations and manage risk at lower cost $[7,35]$. The use of ICTs by global mobile bankers is crucial to access 
real-time information anytime and anywhere. Technology could fail and the users may experience difficulties. In the financial industry, particularly in banking organizations, this failure of technology or inability of users to access information services could lead to serious consequences in terms of loses and impacts on the bank's business. The ICT-support call-centres, therefore, have strategic roles to play in supporting the remote and mobile banking professionals and in enabling global banking organizations to manage the complex implications of their globalisation strategy within the highly competitive global financial industry.

Academics and practitioners have discussed the roles of ICT-support call-centres, e.g. [25, 28, 31]. This paper aims at addressing the crucial role of the ICT-support call-centre in supporting mobile professionals in global banking. The paper adopts a case study approach to discuss how a 24x7 Global Help Desk (GHD) accomplishes this role in a global banking organization. This is achieved through analysis of calls-tracking tickets created in a web-enabled Global Help Desk System (web-based application), which is used for managing all end-users' requests, and facilitates multi-branches global support process. The tickets are created by the GHD analysts as a result of calls that are made by any mobile professionals who work for this global bank. The ticket includes details of the problem and of the solution provided. The tracking-tickets analysis is complemented with ethnographic-based participative observation by the first author who also works as the head of the global help desk and reports to the Chief Information Officer (CIO) in this global banking organization. It is concluded that the conceptualisation of mobile ICT support tasks in terms of pre-, in- and post-mobility support can provide a sound conceptual basis for understanding the challenges of mobile ICT support.

In the following section we discuss related research on mobile professionals and on ICT support centres. Section 3 outlines the research approach and methodology. Section 4 outlines the institutional context of the global help desk within the bank. Section 5 presents the empirical results of analysing the support tickets and classifies these according to the three stages of pre-, in- and post-mobility. Section 6 concludes the paper.

\section{ICT Support Call-Centres for Mobile Professionals}

Modern organizations have been extending their information services and systems to reach out remote sites and mobile workers to sustain competitiveness and address the challenges of the contemporary global economy $[2,24,37]$.

\subsection{The Emergence of Mobile Work}

Rapid growth in laptop computing, personal digital assistants, mobile phones services, wireless technologies, and wide range of mobile ICTs has prompted many organizations to address the needs for managing and supporting this form of extended enterprise $[1,18,38]$. The increasing use of web-based services has further accelerated the global transformations of organization [12]. Many have started to argue that these extended organizations of remotely mobile knowledge workers and executives are destined to become the norm, rather than the exception $[21,22,26]$. The workplace is changing forever and millions of employees around the world work regularly outside the geographical boundaries of the enterprise. This army of location-flexible and nomadic knowledge workers require ICT-supports that enable them to overcome technical problems and difficulties they experience. That creates a challenge for ICT departments and their call-centres in satisfying the enterprise employees (i.e. end users).

\subsection{Mobility and ICT Service Quality}

In measuring ICT service quality, it has been reported that one of the most important factors is the match between users' expectations and the ICT-support [13]. For mobile professionals - the temporal, spatial, and contextual barriers, (see e.g. [20]), associated with mobility work increase the complexity of matching mobile users' expectations to the ICT support efforts. Usersatisfaction can be achieved when the expectations of users are met in terms of response time, problem resolution and the way the ICT support analyst manages his or her communications and interactions with the end-user [31]. Some studies on service-level-agreements suggested that 
end-users can be self-supported when some factors are available such as end users ready for technology learning, needs to gain control, desire for flexibility, and opportunity to reduce cost [28]. Although some mobile professionals may develop self-support skills and ability to solve technical problems, the rapid and continued growth in mobile computing creates the need for consulting the ICT experts such as callcentres support analysts. This model of callcentres and help-desk support units has been adopted by many organizations to meet their service-level-agreements requirements, ensure availability of ICTs to end-users, and manage the risks that could result from technology failure or users' inability to use information services.

Some researchers in the field of ICT servicequality have argued that the dimensions of measuring the quality of ICT service should be: (1) Tangibles such as facilities, equipment, and personnel appearance; (2) reliability in terms of ability to perform the promised service dependently and accurately; (3) responsiveness in terms of willingness to help end users and provide prompt service, (4) assurance represented in knowledge and courtesy of employees and their ability to inspire trust and confidence; and (5) empathy "such as caring" and the individualised attention the service provider gives to the end users, e.g., $[8,25]$. Pitt et al. [31] argue that measuring the difference or gap between the perceived service quality and the expected service quality, suggesting that this gap can be considered as the service quality formula, captures the service quality for each dimension.

\subsection{Potential Complexities}

Although it can be argued that the call-centres' analysts in their support to the remote and mobile professionals can consider measuring the dimensions of perceived quality, the process of measuring service-quality for mobile users might not be an easy task since further complexities are associated with each one of the five dimensions. For remote and mobile users, the tangible dimension, for example, is more complex to measure compared to local-office users, as it could be represented not only in the quality of mobile computing devices and services (e.g. specification, features, setup, etc), but also in how the ICT-support analysts appears to the mobile professionals through their mobile interactions. Similarly, reliability is difficult to measure, as the ability to perform the promised service does not only depend on the analysts but also on the mobile professional's learning capability. Willingness to remotely follow support analyst guiding instructions remotely is also a critical factor. The assurance in terms of knowledge and ability to inspire trust and confidence as well as the empathy in terms of caring and individualised attention, might be highly influenced by the effectiveness of communication between the support analyst and the mobile user. Users' expressions of what they want are revealed from their expectations and their perceptions of what they think they are getting $[30,41]$. The prime determinations of expected services quality are word-of-mouth communications, personal needs, past experiences, and communication by the service provider [31].

\section{Research Methodology}

This research adopts a qualitative approach using a case study research approach. The paper reports on initial empirical findings from analysing requests from mobile professionals for help to a global help desk support unit of a global bank. Content analysis and reflection in action (type of observation) were the primary two methods used in collecting and analysing the research evidence. Results were analysed using interpretivist methods, as this study is founded on interpretive philosophy and based on the assumption that the knowledge of reality is obtained through social constructions such as language, consciousness, shared meanings, documents, tools, and other artefacts [23].

\subsection{Case Study Approach}

This research adopts a case study approach based on which we have investigated how mobile professionals in global banking are supported in regards to their use of mobile ICTs. Yin [40] defines the case study as an empirical inquiry that investigates a contemporary phenomenon within its real-life context when the boundaries between the phenomenon and context are not clearly evident and multiple sources 
of evidence are used. Case studies help in exploring characteristics such as change and other dynamic processes. Creswell [14] describes a case study as an exploration of a "bounded system" or a case (or multiple cases) over time through detailed, in-depth data collection involving multiple sources of information rich in context.

\subsection{Tickets Content Analysis}

The primary method applied was the analysis of global help desk tickets, each reflecting a request reported to the help desk by mobile professionals. The global help desk system had more than 21,000 tickets covering users' requests on different ICT services related to client-server technologies, standard applications, banking systems, and users' interaction services. Although $24 \%$ of the GHD tickets involved supporting users of mobile client devices such as notebooks, mobile phones, PDAs, and TabletPCs, only 1000 support tickets were selected and analysed, since the analysis focused on remote mobility support requests. Content analysis was used in order to understand the categories reflected in the support request tickets $[4,36]$.

\subsection{Reflection-in-Action}

In addition to the analysis of the support tickets directly, the first author of this paper engaged in participant observation and reflection-in-action [33] through his day-to-day role as head of the global help desk reporting to the chief information officer. Barley and Kunda [3] advocate that observation-based techniques provide credible sources of information on what people actually do or how they do it for acquiring detailed, contextually sensitive data on work practices. This technique can reveal the significant and important meanings of professionals' everyday work practices (see e.g. [32]).

\subsection{Unit of Analysis}

Identifying a unit of analysis, considering the research question, is an important methodological step which influences the possible generalisations that can be made at the completion of the research study $[6,19]$. The unit of analysis in this research is the interaction between the bank employee who travels frequently and who use mobile ICT (i.e. mobile professionals) and global help desk (GHD) staff in regard to support work and problems reported to GHD. This involves examining the activities of mobile professionals in reporting technology problems to the GHD, and, at the same time, investigating the activities of the GHD staff in resolving technological issues and helping the bank's mobile professionals prior, during and after travelling.

\section{A Global ICT Support Centre}

This section provides details on the structure and process adopted in this global banking organization to provide day-to-day ICT support to its employees (i.e. the users community).

\subsection{Global Banking Organization}

The Global Help Desk (GHD) is a support unit, which is part of the global information technology (GIT) of a global banking organization that has its head office in Bahrain and has an international network of branches and units worldwide. This banking organization is predominately a wholesale bank with some retail banking activities. Its strategy of diversified growth led to the development of its widespread network of branches, representative offices, subsidiaries and affiliates in over thirty countries around the world, including the principal international financial centres, e.g., London, Paris, New York, Singapore, Milan, Frankfurt, Hong Kong, and also in different business centres of countries such as Sao Paulo, Cairo, Amman, Algeria, Madrid, Tunis.

\subsection{Mobile Professionals in Global Structure}

The bank adopts a hybrid model of organizational structure in which both hierarchal and matrix structures are integrated. While each branch and unit has a management hierarchy that reflects administrative reporting lines and relationships, the matrix structure is meant to address the functional reporting relationships 
between the branches and the senior managements in the head office. Executives and senior managers in the head office have global responsibilities. For instance, the CEO acts as the president of the bank's group worldwide. Executives, senior managers (and even middle level managers) in head office departments, e.g. treasury, operations, credit and risk, global information technology, financial control, audit, legal, human resources, premises and engineering, commercial banking, islamic banking, and retail banking, all have global responsibilities and they are expected to travel around these branches to ensure consistency in strategies, plans and practices. Professionals working in profit-making centres (i.e. departments) are expected to travel worldwide to deal with global clients. Professionals working in supporting centres are also expected to travel to manage global suppliers and provide global support to the bank's units and branches. Due to these global responsibilities, a substantial part of the bank's employees are highly geographically mobile. Moreover, many executives and professionals of both profit centres and support centres are expected to access ICT applications and services from home to manage risk (e.g. market risk, operational risk, etc). To support its global business and the mobility of its professionals, the bank has made large investments to enhance its global technology infrastructure.

\subsection{Mobile Services from Global ICT Infrastructure}

Five years ago, the bank decided to set up a Global Processing Hub (GPH) in its head office, connected through a modern wide area network operative throughout its branches and subsidiaries, to provide the communication infrastructure required to support the new banking systems and to address the needs of its professionals in managing global business. At that time, the bank completed the upgrade of its global telecommunications network to the new global managed data services which connects all wholesale units and disaster recovery centres. This integrated global network infrastructure covers the bank's branches in eight cities in different geographical areas including Middle East, Europe, North Africa, East Asia, and North America. The new network connects the wholesale units to business applications. It also provides enhanced services such as voice services (allowing quick dial facilities for overseas calls at local rates), global e-mail, global storage for data access, information services, and seamless backup capabilities. The bank has also made large investment in mobile ICTs, enabling its mobile professionals to access information services whilst on the move. Mobile computing devices such as laptops, mobile phones, PDAs, and TabletPCs are heavily utilised by the bank's mobile professionals for accessing wide range of information systems and services. Moreover, the bank's mobile professionals use a virtual private network ${ }^{1}$, Internet roaming services ${ }^{2}$, terminal servers technology ${ }^{3}$ and remote access services to connect to different information services and applications using their mobile devices. This networking infrastructure and mobile services are heavily utilised and managed with sophisticated security tools.

\subsection{Global ICT-Support Structure}

The global help desk (GHD) acts as a single point of contact for all end users in the bank. The GHD is a unit in the global information technology department, which includes three other support units: Global application development, global processing hub, and global networking services in addition to its global planning and coordination unit. The GHD provides support on clients' technologies and resolves problems related to any standard or special banking client application software. The global networking services provide support on server and communication technologies. The GPH has the responsibility of administrating the bank's transactional processing and managing the bank's operational systems. The global

\footnotetext{
${ }^{1}$ Virtual private networks (VPN) enable mobile users of the bank to access email, corporate intranet and different web-enabled banking applications.

2 The internet roaming service enables mobile users of the bank to connect to the Internet with local dialup cost. This service enables the bank's mobile users to use VPN globally from different geographical areas with reduced connection cost.

3 Terminal servers technology is a server-based computing that allows mobile users to use their client devices to access network resources remotely and it eliminates the needs for installing ICT services or storing data in the local client machines.
} 
application development unit has the responsibility of designing, developing, customizing and supporting business application systems. These are, for example, in-house applications, banking systems interfaces, reports, e-Banking, Web-based Services.

The ICT support teams are based at the head office in Bahrain. However, they are expected to travel to the bank branches for project implementation purposes as required. There is only a few support staff in each branch to address day-to-day support requirements. Administratively, the local support team reports to the branch management, but functionally they report to the head office global information technology department.

\subsection{Global ICT-Support Process}

The GHD provides $24 \times 7$ hours ICT-support services. Users report their requests of ICT-support by calling a dedicated telephone number, by emailing the department or by creating a support request ticket using the Corporate Intranet, which provides a web-based interface to the global help desk management system. A first level support analysts will receive the request and create a ticket for the user's request in case it is sent by mail or telephone. The ticket will include data fields that provide all necessary details, such as, user name, department, branch, request category, description, priority, service level, and activity log. The analyst will try to support the user through the telephone. If the problem is not resolved through the first level telephone-based support, the analyst will assign the request ticket to a second level support analyst from one of the specialised units, depending on the request category. The second level analyst will be notified using automatic email notification and a telephone call by the first line analyst, and short messaging service (SMS) notification is also used for certain problem categories.

Using a web-based interface, each support analyst in the head office and other branches can access each ticket assigned to him or her, update it, transfer it to another analysts in his branch or to another branch, and finally close it when all tasks are completed. All analysts are provided with mobile phones and laptops to ensure that they are reachable to provide support outside the regular working hours, in case the on-site support analysts require assistance. The first level analyst will monitor the call request tickets' updates, movements and closure by second level analysts. The head of the global help desk has the responsibility of managing this global support process and escalate to the Chief Information Officer (CIO) any issues that require his attention or senior management actions.

\section{Pre-, In- and Post-Mobility}

Luff and Heath [29] categorised mobility into three types: micro mobility, local mobility and remote mobility. Micro mobility is the way in which the artefact may be mobilised and manipulated for various purposes around a relatively circumscribed, or "at hand", domain. Local mobility is more scattered, for instance, walking between rooms, floors and buildings at a local site. Remote mobility is when remote users interact with each other using technology such as the use of mobile ICTs during business trips, client visit or working from home. Analysing the GHD tickets revealed three categories of remote-mobility ICT support tasks; pre-mobility support prior to the mobile professionals leaving; in-mobility tasks generated whilst on the move; and post-mobility tasks emerging upon return. Further analysis of data collected through participant observation has enabled us to capture details and strengthen meanings, which have demonstrated the importance of ICT support to mobile professionals. Figure 1 shows a sample ticket captured from the GHD system. One thousand sample tickets have been analysed using the Interpretation process. In his book Interpreting Quantitative Date, Byrne [10] advocates that quantitative data should be interpreted to provide the necessary understanding in analysing research results. Table 1 provides eight main categories of requests made by mobile users. The tickets content has been qualitatively interpreted and, as a result, they have been categorised into three main categories (i.e. Pre-, In- and Post-Mobility Support Tickets). 


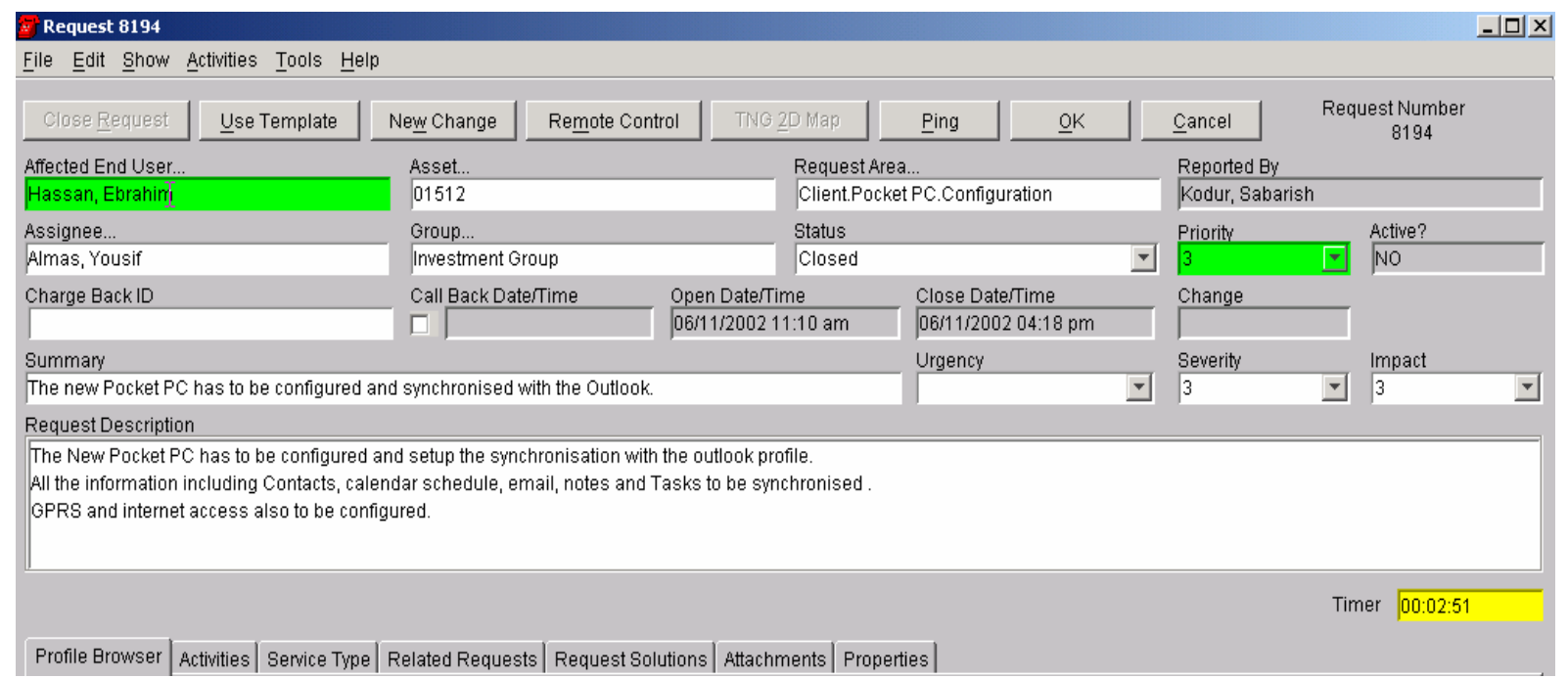

\begin{tabular}{|ll|}
\hline Request Number: & 8194 \\
Open Date-Time: & 11-June-2002 [11:10] \\
Close Date-Time: & 11-June-2002 [16:18] \\
Request Priority: & 3 \\
Request Category: & Client.PocketPC.Configuration \\
Summary: & The new Pocket PC has to be configured and synchronised with the Outlook. \\
Request Description: & The New Pocket PC has to be configured and setup the synchronisation with the \\
& outlook profile. All the information including contacts, calendar schedule, email, \\
& notes and tasks to be synchronised. GPRS and internet access also to be \\
& configured.
\end{tabular}

Fig. 1. Sample of a Request Ticket Created for Mobile User (Pre-Mobility Support).

\begin{tabular}{|c|c|c|c|c|c|}
\hline Request Category * & Pre- & In- & Post- & Total & $\%$ \\
\hline (1) Client.RemoteDesktop.xxxx & 36 & 49 & 21 & 106 & $11 \%$ \\
\hline (2) Client.Laptop.xxxx & 254 & 145 & 46 & 445 & $45 \%$ \\
\hline (3) Client.PocketPC.xxxx & 72 & 43 & 23 & 138 & $14 \%$ \\
\hline (4) Client.TabletPC.xxxx & 21 & 19 & 10 & 50 & $5 \%$ \\
\hline (5) Client.ReuterSmartWatch.xxxx & 41 & 21 & 9 & 71 & $7 \%$ \\
\hline (6) Client.MobilePhone.xxxx & 83 & 9 & 22 & 114 & $10 \%$ \\
\hline (7) Client.SatellitePhone.xxxx & 16 & 3 & 2 & 21 & $2 \%$ \\
\hline (8) Client.OtherDevices.xxxx & 18 & 29 & 8 & 55 & $6 \%$ \\
\hline Total & 541 & 318 & 141 & 1000 & $100 \%$ \\
\hline$\%$ & $54 \%$ & $32 \%$ & $14 \%$ & $100 \%$ & \\
\hline
\end{tabular}

* Request category [.xxxx] indicates sub-categories of the problem/request (e.g. Client.PocketPC.GPRS, Client.Laptop.VPN, Client.RemoteDesktop.TerminalServices, Client.ReuterSmartWatch.Configuration, etc).

Table 1. Analysis and Interpretation of 1000 Sample Tickets (Pre-, In- \& Post-Mobility). 


\subsection{Pre-Mobility Support Tasks}

Prior to their business trips or leaving office, some of the mobile professionals in the bank have developed a routine and practice of calling GHD to check certain ICT services and ask for any new services that they may need for their mobility work. The GHD analysts perform a service verification process using the client inventory systems that store data about all services used in every single client device. All requests that users report prior to their business trips or leaving office are logged in the GHD tracking system. Around 54\% of the analysed tickets are on supporting professionals prior to their remote mobility. Some of these tickets document the mobile users' desire for higher access rights privileges on their laptops. The laptops needed to be temporarily configured for accessing some additional local ICT resources during trips to different branches. Considering the banks' security policy on user access rights, higher access privileges are very restricted. Therefore, for those mobile users, the GHD analysts would configure higher privileges only on local profiles, which should be used in different branches. Close monitoring is performed on these laptops using network monitoring tools in each branch by analysts from various development units, depending on the specific services accessed remotely. This process of monitoring mobile users is audited annually. Records and monitoring logs are provided to both internal and external auditors.

Another group of support tickets reflects that some users, who travel or need to work from home, frequently approached GHD in order to be educated on the use of certain services before travelling or leaving the office. These were in particular newly appointed managers or users who intended to use certain services for the first time. For these users, the GHD analysts provide short training sessions, user-instruction and technical tips. For example when the bank started offering a virtual private network coupled with Internet roaming services, a technical workshop was conducted for each mobile user who requested these. All users were reminded and educated abut the security issues, precautions and risk relevant to the utilisation of virtual private networks in lights of the bank's security policy. Each request was tracked, scheduled and documented using the GHD system. Similarly, when the bank started offering terminal server technology; there was an increase in the number of pre-mobility support tickets for educating those requiring this service. The global ICT department offered terminal server technology as an alternative to the remote access service, particularly for those mobile users who require mission-critical banking applications on their laptops as some central banks do not recommend (but do not prevent) having banking applications on laptops, due to security requirements. Some mobile phone users were also frequently educated on technical aspects such as configuring the mobile phone for accessing web and WAP services, synchronising the mobile phone and workstations for accessing emails, contacts and calendar data. Few tickets also documented the work done by the GHD analysts for educating and supporting satellite phone users who travelled to areas where GSM networks were not available. Hardless et al. [17] have addressed the needs for mobile professionals learning, and as members of the community of practice [39], the bank's mobile professionals have developed this proactive pre-mobility learning.

Evidence of the significance of pre-mobility support tasks has been found also in tickets on supporting PDA devices such as Palm, PocketPC and Nokia Communicators. For instance, prior to and during the recent three-week war in Iraq, many executives and senior mangers called GHD for configuring News web-services such as Reuters on their handheld devices. The bank's executives have been encouraged to use handheld devices as the CIO of the bank distributed 80 Palm Pilots to the bank's executives during board meeting three years ago. During the coffee breaks of that board meeting, the GHD arranged workshops demonstrating to the bank's executives how handheld devices could support their work and how to access services such as email and contact lists. Many executives now use PocketPCs and Nokia Communicators. As they learn about services and applications supported by PocketPCs, they call GHD to get help with configuring these extra services on their PDAs.

The bank provided video conferencing facilities in eight main branches that also are integrated 
through the global helpdesk management system. Prior to their business trips, some of the bank's mobile professionals used video conferencing for the preparatory meetings, which in some cases reduced the duration and cost of business trips. The GHD received video conferencing requests and created GHD tickets that included information about the video conferencing sites, about scheduling and on how the cost of the sessions would be distributed among the participating sites. The GHD analysts in each site (i.e. branch) were expected to coordinate with each other to ensure any technical issues were resolved.

\subsection{In-Mobility Support Tasks}

The bank's global help desk provided 24 hours support throughout the week. Mobile professionals could remotely call GHD any time and from anywhere to obtain support from the analysts available on- and off-site. This support coverage was crucial as the bank operated globally across most time zones. Although some ICT analysts were scheduled to be available onsite covering the 24 hours, the remaining analysts were accessible on their mobile phones outside the normal working hours. Around $32 \%$ of the analysed tickets are on supporting professionals during their remote-mobility. The majority of tickets show that during their remote-mobility, the bank's professionals primarily called the GHD for problems and requests on accessing network services. For instance, the account would lock if the password was entered wrongly three times to access email and corporate intranet services through the virtual private network and two times only if the users were accessing banking applications using the remote access service. Mobile users would ask the GHD to unlock their account and help them to overcome any technical problems they encountered. Over that last decade, some researchers in the IS fields have had social and business theories of risk in studying the ICTs role in managing risk in the financial industry, e.g., $[34,35]$; see also $[5,16]$. For certain users, such as some of the bank's dealers or the ICT professionals who supported the bank's criticalmission applications, the inability of accessing ICT services and applications could potentially result in large loses. This exemplifies the importance of discussing ICT roles in risk management.

Some tickets show that mobile professionals call GHD to be remotely educated on using services that they have not familiarised themselves with prior to their remote mobility or for configuring and installing new ICT services. Those mobile professionals have technical capabilities without which it would be difficult for the ICT support analyst to educate them remotely. Those mobile professionals and their supporting ICT analysts have developed the skills of interacting remotely for solving technical problems. Newly appointed individuals have required time to develop this type of mobile learning culture.

The GHD also offers remote-site support for executives who access the bank's ICT services from their houses. Three GHD support analysts have been trained in communicating with executives and their ICT support requirements such as installation, configuration of desktops, laptops, $\mathrm{ISDN}^{4}, \mathrm{ADSL}^{5}$, Dialup, Satellite, Internet and wide range standard and banking applications and communication services. The increase of this type of support calls, particularly when there are major changes in the executive house or when the executives move to new houses, has prompted the GHD to define problem categories in the GHD tracking system to address the need of categorising this kind or remote site support. The GHD considers these calls as business calls to which high priority responses should be provided, similar to the executives' inoffice ICT support requests. Briere and Heckart [9] argue that while home offices can mirror the employees' office desk setups and, therefore, allow them seamless use of applications, technical problems do arise, including difficulties with connections such as cabling, ISDN access, security, and remote support.

Some tickets reported issues relating to the bank's globally managed data services, that is the wide area network. This would be done either from different branches to the head office, by remote-mobile users who are on busi-

\footnotetext{
${ }_{5}^{4}$ ISDN is Integrated Service Digital Network

${ }^{5}$ ADSL is Asymmetric Digital Subscriber Line
} 
ness trips to the branch, or by users permanently working in the eight integrated branches. The GHD first level analyst was expected to respond promptly and escalate the call to the global networking services analyst, unit head and service provider, if required, depending on the nature of the problem. Outside normal working hours, the global networking services analysts used their laptops for troubleshooting and resolving the problem immediately, as this could greatly impact the bank's business and transactional processing. Delays in resolving global managed data services problems could result in millions of US\$ losses.

During the three weeks war in Iraq, the requests for news subscriptions resulted in the creation of a ticket for each request, which was then transferred to the global networking services unit for implementation. This unit was responsible for administering the news, which included local and global news relevant to the war and which might have impact on the bank's business. Prior to the start of the war, the bank performed intensive testing on its disaster recovery set-ups and prepared business continuity plans in which scenarios were created to address the need for switching to the disaster recovery sites in Europe or the Middle-East. The head office building was in the diplomatic area full of foreign embassies and political institutions. Peaceful demonstration took place close to the head office, and could potentially have impacted the bank, had they gone out of control. Using the news services, the bank's mobile users were updated and notified about any local and global developments. Some users even started to send news directly to the global networking services team responsible for broadcasting news.

\subsection{Post-Mobility Support Tasks}

Upon their return from, for example, business trips or from home, some the bank's mobile professionals would ask GHD analysts to assist in performing certain tasks and to resolve problems that were encountered and unresolved. Around $14 \%$ of the analysed tickets were of this type. Users would, for example, ask about the best methods to complete the backup of any data from their laptops, PDAs, or tablet PCs to their network space. The security policy emphasised that users should regularly backup their data to the network since all business data should be kept on the network. Leaving sensitive data on fixed, portable or mobile workstations without regular transfer to the network could result in sanctions and serious disciplinary actions up to dismissal from job.

GHD analysts also observed that some users using laptop while travelling developed a routine of leaving laptops in their office after their return. Most of the bank's offices were in open-office environments, which made the laptop subject to internal security risks despite the building security arrangements that protected resources from some of the external risks and hazards. These observations were reported to the CIO who instructed the GHD analysts to start taking these laptops to the GHD workshops without the knowledge of those users. When they returned to the office next morning, those users would panic and report the loss of their laptop. Consequently, the GHD started to arrange for laptop locks for those users who need their laptops for business trips only. In his structuration theory, Giddens [15] argues that sanctions (as interaction) reproduce legitimation (as structure) through norms (as modality). The two examples above exemplifies this reproduction process where structure, norms (i.e. rules), and sanctions reproduce each other.

\section{Conclusion}

In this paper, we have demonstrated the significant role of ICT call-centres in supporting mobile professionals in a global banking organization. Both ICT support analysts and mobile professionals have developed mobile learning skills that enable them to interact prior, during and after remote mobility to address mobile ICTs support requirements. The ICT support services that the global support call centre provided for remotely mobile users have been classified into three categories: Pre-Mobility, InMobility, and Post-Mobility. The study clearly demonstrates that the issues related to establishing mobile organizations go far beyond procuring mobile and wireless devices. Mobile working requires mobile support and this implies an extensive support infrastructure ensuring proper use and support of the technologies. 


\section{References}

[1] A. Al-Taitoon, C. Sørensen, and D. Gibson, Modern Professionals and Their Tools: ICT Supporting Organizational Flexibility and Control, in Proceedings of 11th European Conference of Information Systems, Naples, Italy, 2003.

[2] C. Avgerou, Information Systems and Global Diversity, Oxford University Press, Oxford, UK, 2002.

[3] S.R. BARELEY AND G. KundA, Bringing Work Back, Organ. Sci. (2001), vol. 12, no. 1, pp. 76-95.

[4] M.W. BAUER AND G. GASKELL, Researching with Text, Image and Sound: A Practical Guide, Sage, London, 2000.

[5] U. BECK, Risk society: Towards a new modernity, Sage, London, 1992.

[6] I. Benbasat, D.K. Goldstein, And M. Mead, The Case Research Strategy in Studies of Information Systems, MIS Quarterly (1987), no. September, pp. 369-386.

[7] A.N. BERGER, Q. DAI, S. ONGENA, AND D.C. SMITH To what extent will the banking industry be globalized? A study of bank nationality and reach in 20 European nations, Journal of Banking \& Finance (2003), vol. 27, pp. 383-415.

[8] L.L. Berry, A. PARasuraman, AND A.V. ZeiTHAML, Improving Service Quality in America: Lessons Learned, Academy of Management Executive (1994), pp. 32-52.

[9] D. BRIERE AND C. HECKART, The real implementation questions, $N W W(1995)$, vol. 12, no. 41, pp. 18.

[10] D. BYRNE, Interpreting quantitative data, Sage, Thousand Oaks, California, 2002.

[11] M. CASTELLS, The rise of the network society, Blackwell, Oxford, 1996.

[12] M. CASTElls, The Internet Galaxy: reflections on the Internet, Business, and Society, ed. Manuel Castells, Oxford University Press, Oxford, 2001.

[13] D.W. ConRath And O.P. Mignen, What is Being Done to Measure User Satisfaction with, Information and Management (1990), vol. 19, no. 1, pp. 7-19.

[14] J.W. CRESWELL, Research Design: Qualitative and Quantitative Approaches, Sage, London, 1994.

[15] A. GIDDEns, The constitution of society, Polity Press, Cambridge, 1984

[16] A. GIDDENS, Risk and Responsibility, The Modern Law Review (1990), vol. 62, no. 1.

[17] C. Hardless, J. Lundin, AND U. Nulden, Mobile Competence Development for Nomads, in Proceedings of Thirty-Forth Hawaii International Conference on System Sciences (HICSS-34), Big Island Hawaii, USA, 2001.
[18] S.L. JARVENPAA AND B. IVES, The Global Network Organization of the Future: Information Management Opportunities and Challenges, Journal of Management Information Systems (1994), vol. 10, no. 4 , pp. $25-57$.

[19] C.M. JudD, E.R. SMITH, AND L.H. KIDDER, Research Methods in Social Relations, Holt, Rinehart, and Winston, Inc, Toronto, 1991.

[20] M. Kakihara And C. Sørensen, Mobility: An Extended Perspective, in Proceedings of $35 \mathrm{th}$ Hawaii International Conference on System Sciences (HICSS-35), Big Island, Hawaii, 2002, IEEE.

[21] M. KaKihara And C. SøRensen, Post-Modern Professionals Work and Mobile Technology, in Proceedings of Information Systems Research Seminar in Scandinavia (IRIS'25), Denmark, Copenhagen Business School, 2002.

[22] M. Kakihara, C. Sørensen, and M. Wiberg, Fluid mobile work, in Proceedings of 1st Global Mobile Roundtable, Tokyo, Japan, ed. Takeishi. Institute of Innovation Research (IIR), Hitotsubashi University, 2002.

[23] B. KAPlan AND J.A. MAXWELl, Qualitative Research Methods for Evaluating Computer Information Systems, in J. G. Anderson, C.E. Aydin, and S.J Jay, ed., Evaluating Health Care Information Systems: Methods and Applications, Sage, Thousand Oaks, 1994, pp. 45-68.

[24] D. Kellner, Globalization and the Postmodern Turn, http://www.gseis.ucla.edu/courses / ed253a/dk/GLOBPM.htm, UCLA, 1997.

[25] W.J. Kettinger AND C.C. LeE, Pragmatic Perspectives on the Measurement of Information Systems Service Quality, MIS Quarterly (1997), vol. 21, no. 2 (June), pp. 223-240.

[26] S. Kristoffersen AND F. LJUngberG, Mobility: From Stationary to Mobile work, in Kristin Braa, Carsten Sørensen, and Bo Dahlbom, ed., Planet Internet, Studentliteratur, Lund, 2000, pp. 41-64.

[27] A. KUMAR AND P. PALviA, Key data management issues in a global executive information system, Industrial Management \& Data Systems (2001), vol. 101 , no. 4, pp. 153-164.

[28] R.L. LeIthelser AND J.C. Wethrbe, Service Support Levels: An Organised Approach to End-User Computing, MIS Quarterly (1986), vol. 4, no. Dec, pp. 337-349.

[29] P. LUFF AND C. HEATH, Mobility in Collaboration, in Proceedings of Proceedings of ACM 1998 Conference on Computer Supported Cooperative Work, ACM Press, 1998.

[30] A. Parasuraman, V.A. Zeithaml, AND L.L. BERRY, SERVQUAL: A Multiple-Item Scale for Measuring Customer Perceptions of Service Quality, Journal of Retailing (1998), pp. 12-40. 
[31] L.F. PITT, R.T. WATSON, AND C.B. KaVAN, Service quality: a measure of information systems effectiveness, MIS Quarterly (1995), vol. 9, no. 2, pp. 173-187.

[32] P. RABINOW, Representations are Social Facts: Modernity and Post-Modernity in Anthropology, in Clifford and Marcus, ed., Writing Culture: The Politics and Poetics of Ethnography, University of California Press, 1986.

[33] D.A. SchöN, The Reflective Practitioner: How Professionals Think in Action, Basic Books,New York, 1983.

[34] S.V. ScoTT, IT-Enabled Credit Risk Modernisation: A revolution under the cloak of normality, Accounting, Management and Information Technology (2000), vol. 10, no. 3, pp. 221-255.

[35] S.V. SCOTT AND M.I. BARRETT, The Development of Electronic Trading in the Futures Industry: Strategic Risk Positioning in a Globalizing Age, in Proceedings of Social Studies of Finance Conference, New York, 2002.

[36] D. Silverman, Doing Qualitative Research: A Practical Handbook, Sage, London, 2000.

[37] C. SøREnSEn AND M. KaKIHARA, Knowledge Discourses \& Interaction Technology, in Proceedings of Managing Knowledge: Controvercies and Critiques. International Conference, 10-11 April, Leicester University, UK, 2001.

[38] C. SøRENSEN, L. MATHIASSEN, AND M. KAKIHARA, Mobile Services: Functional Diversity and Overload, in Proceedings of Mobile Computing in the 21st Century, Budapest, Hungary, 2002.

[39] E. Wenger, Communities of Practice: Learning, Meaning, and Identity, Learning in Doing: Social, Cognitive, and Computational Perspectives, ed. Roy Pea, John Seely Brown, and Jan Hawkins, Cambridge University Press, Cambridge, 1998.

[40] R.K. YIN, Case Study Research: Design and Methods, Second ed., Applied Social Research Methods Series, ed. Diane S. Foster, vol. 5, Sage Publications, Inc., Thousand Oaks, 1994.

[41] V.A. Zeithaml, A. Parasuraman, AND L.L. BERRY, Delivering Quality Service - Balancing Customer Perceptions and Expectations, The Free Press, New York, 1990.

[42] S. ZubofF AND J. MAXMIN, The Support Economy: Why Corporations Are Failing Individuals and The Next Episode of Capitalism, Viking Press, 2002.

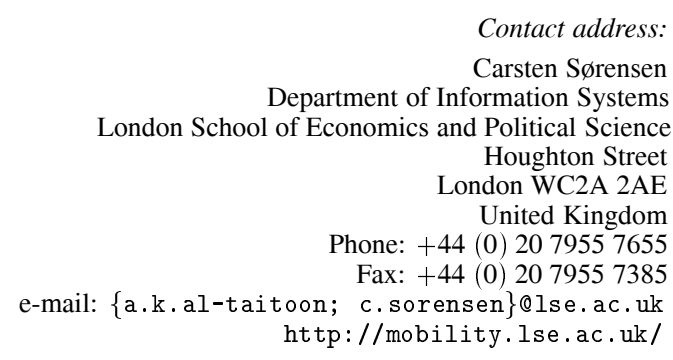

CARSTEN SøRENSEN is a Senior Lecturer in Information Systems at The London School of Economics and Political Science, United Kingdom. He holds a BSc. in mathematics, an MSc in computer science and a $\mathrm{Ph}$.D. in information systems from Aalborg University, Denmark. His research investigates how ICT shapes and is shaped by working practices, most recently mobile and wireless technologies. Core concerns in his research has been the management of social interaction in distributed settings, in particular considering the increased mobilisation of interaction and the subsequent struggle for mobile individuals to engage in fluid interaction. Dr. Sørensen has through the past 14 years been affiliated with a number of Danish, Swedish and British institutions. In 2002 Dr Sørensen initiated a research network in mobile interaction called mobility@1se (http://mobility.lse.ac.uk/), which aims at drawing together academics and practitioners with an interest in studying the profound changes to society, individuals and technologies in the mobile society of the $21^{s t}$ Century. He has since 1997 been Research Director of Laboratorium for Interaction Technology (http://laboratorium.htu.se) at Trollhättan Uddevalla University, Sweden, which is actively engaged in large regional development projects funded by the European Union, Swedish funding agencies and local industries and public organizations

ADEL AL-TAITOON is a PhD Research student in the Information Systems Department at The London School of Economics and Political Science, United Kingdom. He holds a BSc. in computer engineering, an MSc in digital electronics engineering from Cardiff University. His $\mathrm{PhD}$ research in LSE investigates the use of mobile ICTs by foreign exchange traders of global banking organization. This $\mathrm{PhD}$ research focuses on how mobile ICT shapes and is shaped by working practices of foreign exchange traders in fast moving financial markets. Adel is also currently working as an Assistant Vice President in the strategic IT planning and project management unit within the Global Information Technology (GIT) department of the Arab Banking Corporation $(\mathrm{ABC})$. The GIT department is the central global hub for managing ABC IT resources and systems in different branches in the world including Bahrain (Head Office), London, Paris, Milan, Spain, Frankfurt, New York, Brazil, Egypt, Algeria, Tunis, Singapore, Hong Kong and Jordan. Adel has been responsible for the management and implementation of different IT projects related to both wholesale and retail core banking systems, global data warehouse system, e-banking, global support tracking system, e-procurement \& strategic sourcing, security enhancement, mobile technology deployment and different informational systems and technologies. Before joining ABC four years ago, Adel spent seven years in Bahrain Training Institute (BTI) as the Head of Computer and Information Technology Department leading a large team of highly qualified lecturers drawn from different geographical areas including Middle East, Europe, North America and Asia. Adel has also worked in different information technology and telecommunication companies such as AT\&T, NCR and Bahrain Telecommunication Company (BATELCO). 